\title{
SCIENTIFIC RESEARCH AND ITS ROLE IN DEVELOPING THE SKILLS OF \\ FACULTY MEMBERS IN THE LIGHT OF QUALITY STANDARDS AND PERFORMANCE EVALUATION AT THE UNIVERSITY OF TRIPOLI
}

\section{Istanbul / Türkiye \\ p. $702-717$}

Received: $19 / 11 / 2021$

Accepted: 06/12/2021

Published: 01/01/2022

This article has been scanned I iThenticat No plagiarism detected

\author{
Abdegadir Emhammed Salih MANSOUR ${ }^{1}$
}

\begin{abstract}
:
Scientific research eventually considered as one of the most important functions and tasks undertaken by the university, and it is a balancing function to the function of education. Thus, universities have become concerned in the process of discovering, transferring and developing knowledge, and that their role is not limited to preparing specialized educates needed by the labor market. Scientific research also contributed to activating the role of The university in developing and serving communities, which imposed on the university to undertake a new mission that led to the necessity of linking the university with the community, and therefore the functions of the university steadily developed. Development, and therefore the university is entrusted with integrated tasks and functions that it performs through its specialized colleges and scientific centers.

University institutions have great significance in carrying out scientific research and development, transferring knowledge and technology to a variety of fields and activities of society, where scientific research contributes to adapting and keeping pace with global changes and challenges in the long and near term. We found that developed countries follow in this field many means, including provision of services Education, training for the community, and encouraging universities to carry out scientific research, and also development through their faculty promotion system. The topic of scientific research and its role in developing the skills of faculty members is among the topics that are of great significance at all local and international levels, where university education faces in This era of scientific and technological changes and developments, compulsory on universities to develop and modernize their educational system by paying attention to scientific research, so that they could have constructive possessions in improving the stage of students, in their scientific construction, and forming their characters.
\end{abstract}

Key words: Scientific Research, Quality Standards, Developing Skills.

http://dx.doi.org/10.47832/2717-8293.15.48

1 iD Dr. , Siirt-University,Libya, agsdadaa12345678@gmail.com, https://orcid.org/0000-0002-5621-3801 


\section{البحث العلمي ودوره في تطوير مهارات أعضاء هيئة التدريس في ضوء معايير \\ الجودة وتقييم الأداء بجامعة طرابلس \\ عبدالقادر الحممد صالح منصور 2}

الملخص:

يُعد البحث العلمي أحد أهم الوظائف والمهام التي تقوم بها الجامعة، وهي وظيفة مكملة لوظيفة التعليم، وبذلك

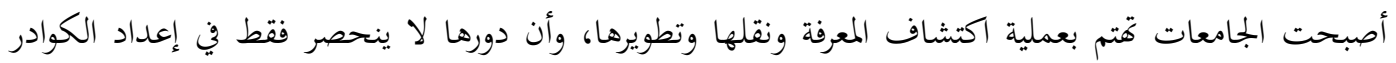

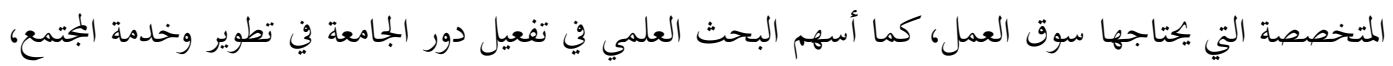
الأمر الذي فرض على الجامعة القيام بمهمة جديدة أدت إلى ضرورة ربط الجامعة بالمجتمع، وبالتالي أصبحت وظائف الجامعة تتطور بالتدريج، فبعد أن كانت وظيفتها تقتصر على التدريس ونقل المعرفة تطورت لتشمل

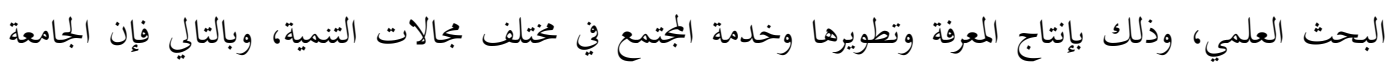

مناطة بمهام ووظائف متكاملة تقوم بما من خلال الكليات والمراكز العلمية المتخصصة بها.

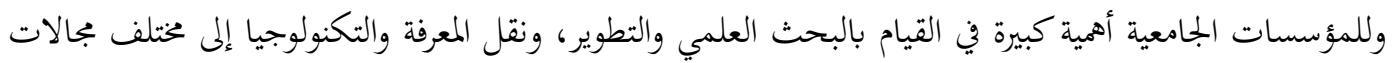
ونشاطات البجتمع، فالبحث العلمي يُسهم في ملاءمة ومواكبة التغيرات والتحديات العالمية على المدى البعيد والقريب، فنجد الدول المتقدمة تتبع في هذا المجال العديد من الوسائل من ضمنها تقديم الخدمات التعليمية والتدريبية للمجتمع، وتشجيع الجامعات على القيام بالبحث العلمي والتطوير من خلال نظام ترقية أعضاء هيئة

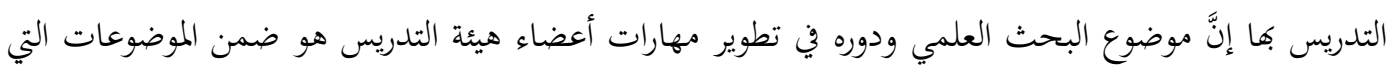

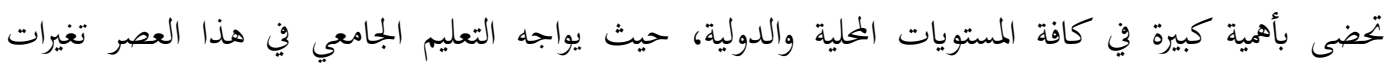
وتطورات علمية وتكنولوجية، فرضت على الجامعات تطوير وتحديث النظام التعليمي بها من خلال الاهتمام بالبحث العلمي، حتى تتمكن من أحداث تأثيرات إيهابية في تحسين مستوى الطلاب، ويف بنائهم العلمي، الكلمات المفتاحية: البحث العلمي، معايير الجودة، تطوير مهارات.

يُعد البحث العلمي من أهم الوظائف الأساسية التي تقوم بها الجامعة التي تؤدي دورا مهما في عملية التنمية من خلال

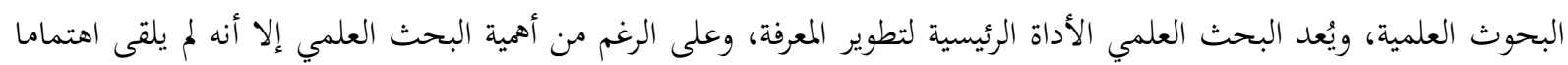
كبيرا وانتشارا واسعا بين الجامعات العربية، لذلك نجد أن كثيرا من البحوث والدراسات العلمية بتحى لأغراض الترقية العلمية لأعضاء هيئة التدريس بالجامعات في مختلف التخصصات والتي متتم بالناحية الفكرية أكثر من اهتمامها بالناحية التطبيقية، إضافة

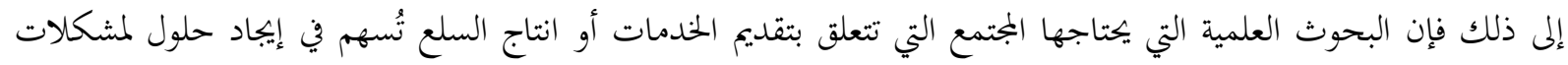

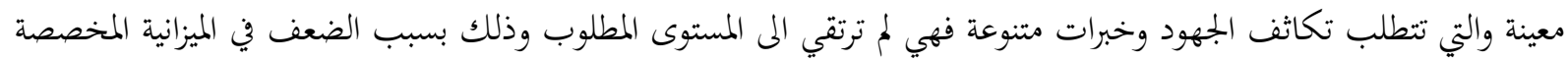

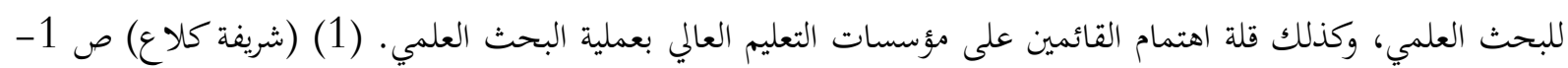


وللمؤسسات الجامعية أهمية كبيرة في القيام بالبحث العلمي والتطوير، ونقل المعرفة والتكنولوجيا إلى مختلف بجالات

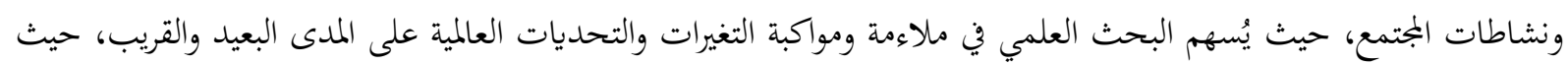

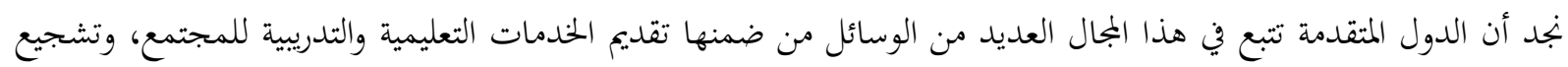

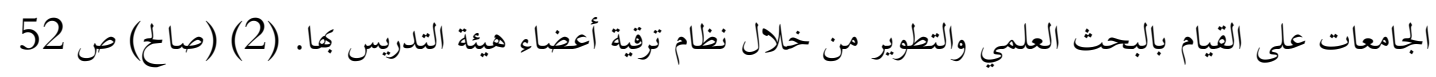
وُو عد عضو هيئة التدريس أحد أهم عناصر العملية التعليمية لما له من دور بارز ومهم في الارتقاء بالمستوى المعريف والعلمي

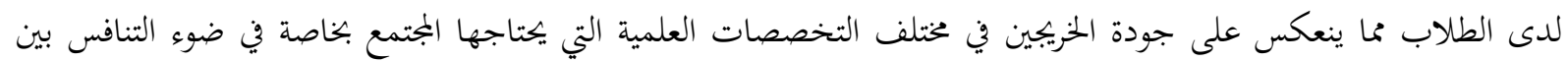
الجامعات في ظل التغيرات، والتطورات التكنولوجية، والمعرفية وثورة الاتصالات والمعلومات مما فرض على مؤسسات التعليم الجامعي

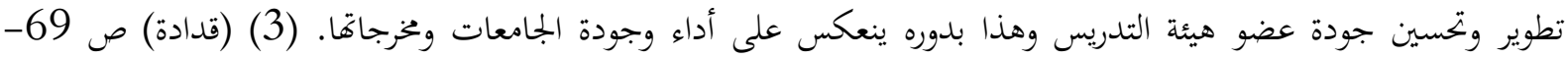

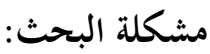

يُعد عضو هيئة التدريس أحد أهم العناصر المؤثرة في العملية التعليمية بالجامعة لما يمتلكه من مهارات وقدرات في مجال تخصصه بتعله في مواجهة العديد من المشكلات التي تعترضه أثناء تأديته لعمله كعضو هيئة تدريس جامعي، كما يمكن له بهذه الحصيلة المعرفية والمهارات والقدرات أن يخوض في مجال البحث والدراسة، والاسهام في حل الكثير من المشكلات التي تواجه

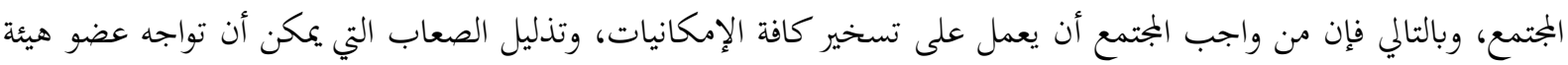
التدريس الجامعي في أداء عمله على أكمل وجه، وذلك للحاجة الماسة الى عضو هيئة تدريس تتوافر له كل الإمكانيات المهنية والتدريسية والعلمية والتي تؤثر بشكل إيجابي في المنتج التعليمي.

ويواجه التعليم الجامعي بليبيا العديد من المشكلات خصوصاً تلك التي تتعلق بأعضاء هيئة التدريس بالجامعات وتقف هذه المشكلات حائلاً دون تطوير مهاراتم وقدراقم، في ضوء معايير الجودة وتقييم الأداء. فقد أثبت بعض الدراسات ضعف تشجيع الجامعات الليبية لأعضاء هيئة التدريس على المشاركة في الندوات والمؤتمرات

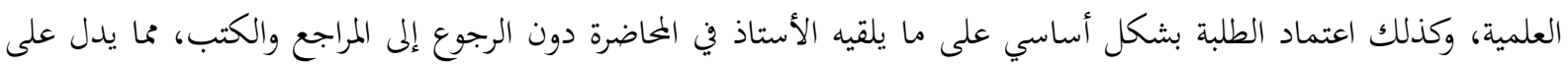
أهمية التطوير لقدرات عضو هيئة التدريس الجامعي.

كما اتضح ضعف متابعة عضو هيئة التدريس لما يستجد في ميدان تخصصه، وغياب التخطيط العلمي لإعداد الأستاذ الجامعي، وقلة مساهمه في القيام بالبحث العلمي، وضعف توافر فرص حقيقية لعضو هيئة التدريس للتدريب على استخدام التقنية

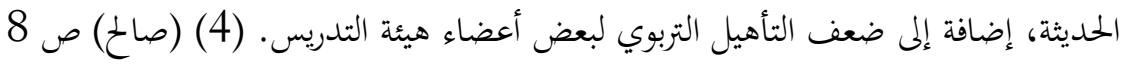
ومما سبق يتضح تأثير بعض المشكلات التي تواجه التعليم الجامعي الليبي على أداء وقدرات أعضاء هيئة التدريس بالجامعات الليبية مما يتطلب القيام بالبحوث والدراسات لتحسين وتطوير أداء عضو هيئة التدريس الجامعي مهنيا، وعلميّاً وأكاديميا من أجل قيامه بدوره الفعال في الجامعة، والرقي بمستوى طلابها، والمساهمة في تطوير وتنمية المجتمع. ويُعد تطوير قدرات أعضاء هيئة التدريس عملية ضرورية وملحة، وهذا لا يتحقق إلا بمواجهة تلك المشكلات والعوائق التي يواجها النظام التعليمي بالجامعات الليبية، ومن ثم تطوير قدرات ومهارات أعضاء هيئة التدريس، وتحسين أدائهم التعليمي والتدريسي من أجل الاسهام في تحسين مستوى الطلاب، الذى يؤدى إلى خخرجات ذات كفاءة عالية قادرة على الاسهام الفاعلة

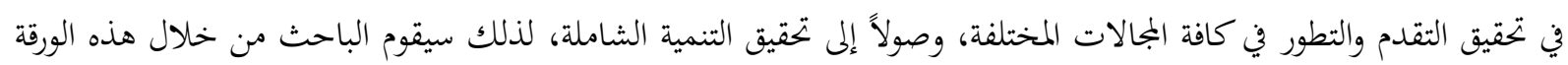


بالبحث والدراسة للدور الذي يمكن أن يقوم به البحث العلمي في تطوير قدرات ومهارات أعضاء هيئة التدريس بجامعة طرابلس

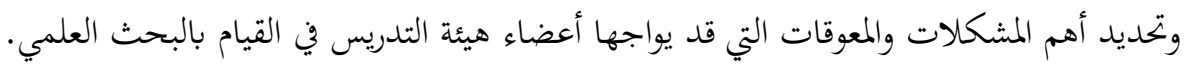

\section{مشكلة البحث}

- ما دور البحث العلمي في تطوير مهارات أعضاء هيئة التدريس في ضوء معايير الجودة بجامعة طرابلس؟ ويتفرع من هذا السؤال الأسئلة الآتية:

- ما أهم المشكلات والمعوقات التي يواجها أعضاء هيئة التدريس في القيام بالبحث العلمي بجامعة طرابلس؟

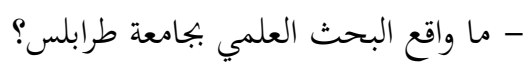
- ما أهم المهارات والقدرات التي يجب أن تتوفر في عضو هيئة التدريس بجامعة طرابلس؟

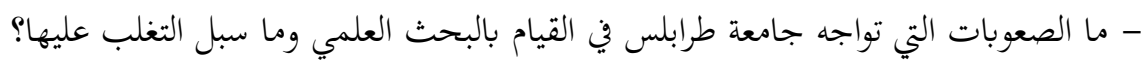

إنَّ موضوع البحث العلمي ودوره في تطوير مهارات أعضاء هيئة التدريس هو ضمن الموضوعات التي تحضى بأهمية كبيرة في كافة المستويات المحلية والدولية، حيث يواجه التعليم الجامعي في هذا العصر تغيرات وتطورات علمية وتكنولوجية، فرضت على على فئل

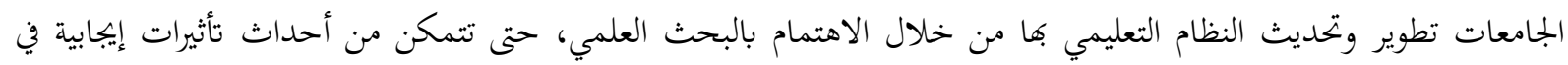
تحسين مستوى الطلاب، وفي بنائهم العلمي، وتكوين شخصيتهم. وتتحدد أهمية البحث في النقاط الآتية: - الاهتمام بالجامعات الليبية من خلال تطوير عمليات البحث العلمي باعتبارها المؤسسات التي تعمل على مد المجتمع بأهم الكفاءات والمخرجات التي يطلبها سوق العمل اللبيي. - - حاجة الجامعات الليبية الملحة إلى التطوير والتحديث في المنظومة التعليمية بخاصة فيما يتعلق بالبحث العلمي لمواجهة التغيرات والتطورات العلمية والتكنولوجية.

- تفيد هذه الدراسة في توجيه المهتمين بالتعليم الجامعي نحو الاهتمام بتطوير العملية التعليمية، والتعرف على الصعوبات التي تعوق الجامعات في القيام بالبحث العلمي وكيفية التغلب عليها.

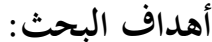

الكشف عن واقع البحث العلمي بجامعة طرابلس.

التعرف على الصعوبات التي تعيق أعضاء هيئة التدريس بجامعة طرابلس في القيام بالبحث العلمي. التعرف على الدور الذي يقوم به البحث العلمي في تطوير قدرات ومهارات أعضاء هيئة التدريس بجامعة طرابلس. تحديد أهم الصعوبات التي تواجه جامعة طرابلس في القيام بالبحث العلمي وكيفية التغلب عليها. تطوير قدرات ومهارات أعضاء هيئة التدريس بجامعة طرابلس. الكشف عن الحلول التي تسهم في تذليل صعوبات القيام بالبحث العلمي. 
حدود بشرية: وتشمل أعضاء هيئة التدريس الذين يباشرون عملهم الأكاديمي في جامعة طرابلس بصفة رسمية بمختلف الكليات.

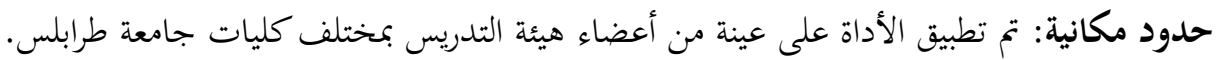

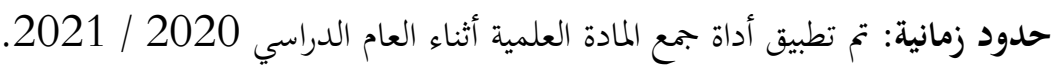

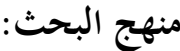

يستخدم الباحث المنهج الوصفي لجمع وتلخيص البيانات والمعلومات المتعلقة بالظاهرة موضوع البحث وإجراء التحليلات الاحصائية واستخلاص النتائج، ودراسة العلاقة بين المتغيرات إضافة إلى استخدام المنهج التحليلي من أجل التحليل والنقد

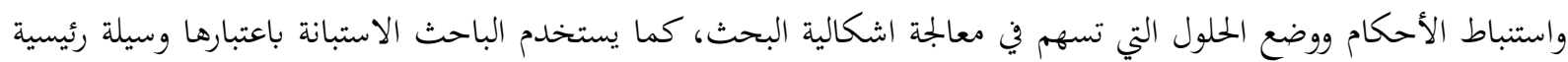
في عملية جمع البيانات والمعلومات اللازمة لاستكمال البحث.

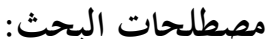

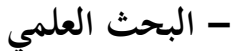

يعرف البحث العلمي على أنه " عملية فكرية منظمة يقوم بها الباحث من أجل تقصي الحقائق يشان مسالة أو مشكلة

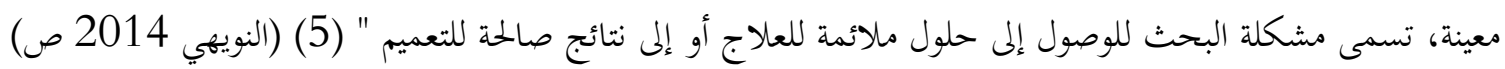

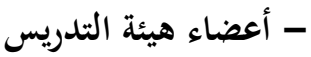
هم " كل من يحمل مؤهلا علمياً عالياً في أحد بجالات العلوم الأساسية التطبيقية، أو الإنسانية ويشغل درجة أستاذ، أو

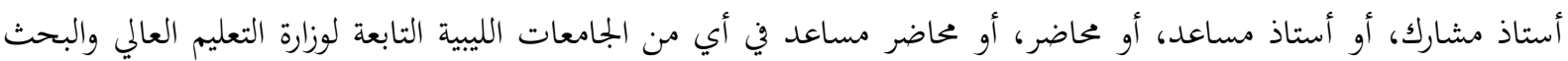

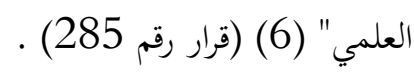

- الجودة -

هي " أسلوب لوصف جميع الأنظمة والمواد والمعايير المستخدمة من قبل الجامعات، ومعاهد التعليم للحفاظ على مستوى

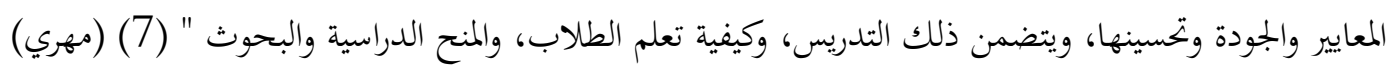

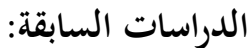

دراسة (الحويطي 2017) وكان من أهم اهداف هذه الدراسة التعرف على معوقات الانتاجية العلمية لعضو هيئة التدريس بجامعة تبوك من وجهة نظر أعضاء هيئة التدريس بها، وتم استخدام المنهج الوصفي المسحي، وكان من أبرز نتائج هذه الدراسة عدد من المعوقات أهمها (كثرة الأعباء الإدارية والتدريسية، وضعف مشاركة الباحثية ونين وقلة حضورهم للمؤتمرات الدولية والاقليمية، وكذلك ندرة وجود حاضنات بحثية داخل الجامعة، وغياب القطاع الخاص عن المشاركة وتمويل البحث العلمي، وأوصت هذه ونه

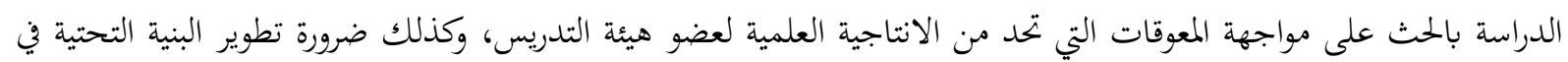
الجامعة للحد من المعوقات التي تواجه الباحثين في مجال البحث العلمي دراسة (العمايرة واخر 2008) هدفت هذه الدراسة إلى التعرف على معوقات البحث العلمي لدى أعضاء هيئة التدريس

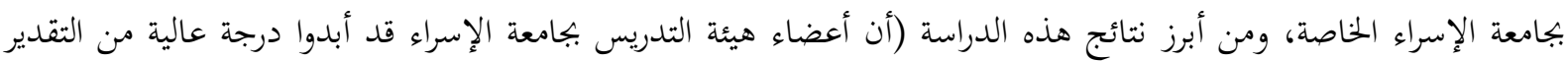


لوجود معوقات تواجهمم في البحث العلمي، ومن أهم هذه المعوقات (عدم وجود بجلة محكمة في الجامعة، وقلة التعاون مع

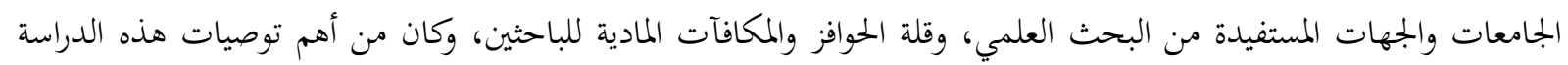
(ضرورة العمل على إيجاد مجلتين محكمتين تابعتين لجامعة الإسراء وأحداهما للعلوم الإنسانية والاجتماعية، والثانية للعلوم التطبيقية. دراسة (العبدلي 2017) هدفت هذه الدراسة إلى معرفة معوقات البحث العلمي لدى أعضاء هيئة التدريس في كلية التربية للبنات بالجامعة العراقية، ومن أهم نتائج هذه الدراسة (وجود معوقات تؤثر بشكل كبير على حركة البحث العلمي في كلية التربية

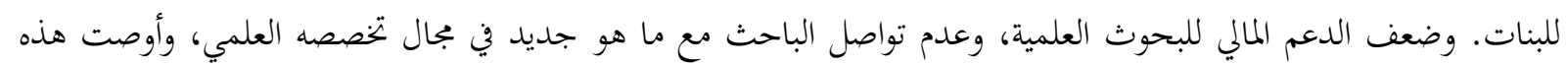

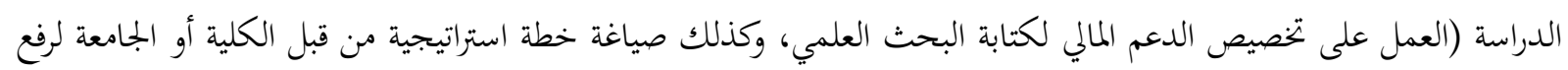
جودة البحث العلمي وفق المقاييس العالمية، أو العربية.

\section{التعليق على الدراسات السابقة:}

لقد أشارت الدراسات السابقة إلى وجود بعض المعوقات التي تواجه أعضاء هيئة التدريس بالجامعات، حيث اتضح من

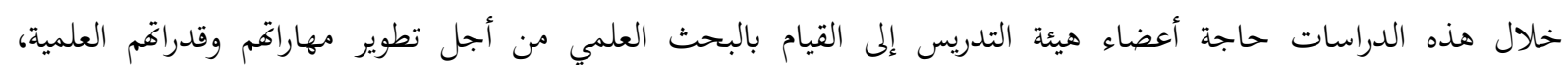

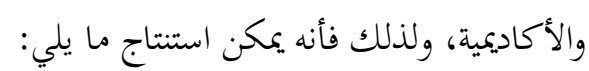
- من أهداف الدراسات السابقة هو التعرف على المعوقات التي تواجه أعضاء هيئة التدريس بالجامعات في القيام بالبحث العلمي، وهذا ما اتفق مع الدراسة الحالية - اتفاق الدراسات السابقة على وجود بعض المعوقات التي تواجه أعضاء هيئة التدريس في القيام بالبحث العلمي - اقترحت الدراسات السابقة بعض الحلول لمواجهة هذه المعوقات وهذا ما اختلف مولف مع الدراسة الحالية.

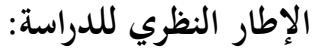

تبذل مؤسسات التعليم الجامعي كثير من الجهود والمحاولات لربط البحث العلمي باحتياجات المجتمع لما لها من دور في عملية صنع القرارات والتأثير في ابتاهات الطلاب والباحثين وتكوين شخصيتهم بتحاه البحث والاسهام في مواجهة المشكلات

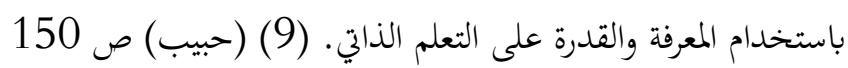

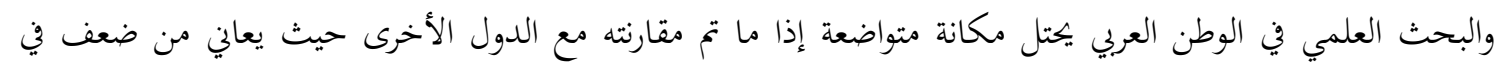

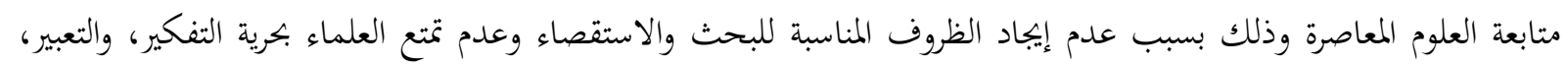
وتوفير الإمكانيات لهم. (10) (مريزيق) ص 136

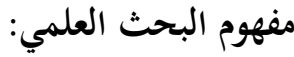

يُعد البحث العلمي أحد أهم الأسباب للتطور العلمي، والتنمية لما له من دور أساسي في التنمية الشاملة، ويساعد أيضا

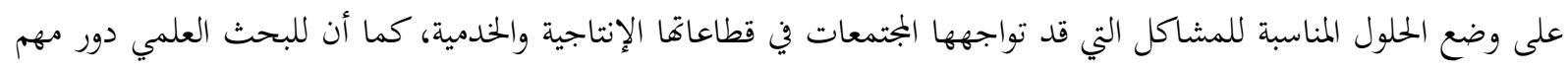

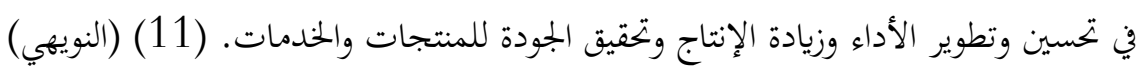
لذلك يمكن القول بأن البحث العلمي هو وسيلة الاستعلام والاستقصاء المنظم والدقيق لغرض اكتشاف معلومات أو

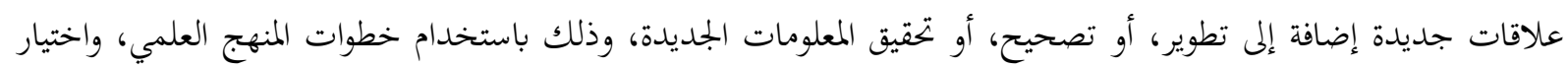

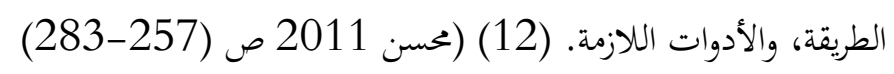




\section{أهمية البحث العلمي:}

يُعد البحث العلمي من أهم الركائز التي يقوم عليها التطور والازدهار، وتدفع عجلة التطور إلى الأمام في مختلف مجالات الحياة، ويساعد في التغلب على الصعوبات وحل المشكلات التي تواجهنا في خختلف المجالات، ويعد الوسيلة التي يحقق بها الانسان سعادته، ورفع المستوى الفكري والثقافي والاجتماعي للباحث، وإضافة جديدة للمعرفة والعلم ورفع كفاءة الفرد وتقليل التكلفة المتعلقة بإنجاز عمل معين، وزيادة الانتاجية، والحصول على الدرجات العلمية. (13) (علي 2019 ص 1-34) وتُعد الحاجة إلى البحث العلمي في وقتنا الحاضر أشد منها في أي وقت مضى، حيث أصبح العالم في سباق الوصول إلى أكبر قدر ممكن من المعرفة الدقيقة المثمرة التي تكفل الراحة والرفاهية للإنسان وتضمن له التفوق على غيره، وبما أن الجامعة مؤسسة انتاجية، تعمل على إثراء المعرفة، وتطوير الفنون الانتاجية، وإعداد الكفاءات البشرية، وصناعة الأجيال وتنشئتها علميا وفكريا

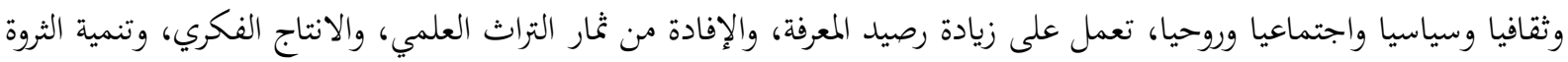

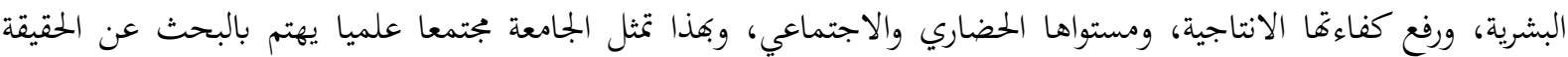
العلمية، فيحتل البحث العلمي موقعا هاما ضمن مسؤوليات عضو هيئة التدريس في الجامعات، الذي يتطلب منه أن يقوم بجهد علمي منظم يهدف إلى تنمية المعرفة الإنسانية في حقل اختصاصه إضافة إلى التدريس، وتولى الجامعة في الوقت الحاضر البحث العلمي عناية كبيرة تلتزم بتوفير الجوو الملائم والإمكانات اللازمة ليقوم أعضاء هيئة التدريس فيها بإجراء البحوث العلمية العية الأصيلة

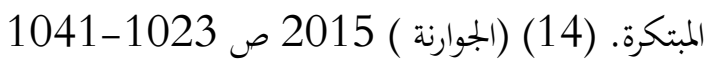

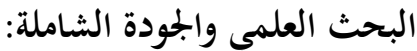

لقد كان للجامعات اهتماما كبيرا بإدارة وتطبيق معايير الجودة بهدف تطوير وتحسين مخرجات العملية التعليمية في كافة التخصصات العلمية، وتحسين مستوى الانتاجية العلمية وتطوير مستوى الأداء المؤسسي وتتمثل معايير جودة عضو هيئة التدريس

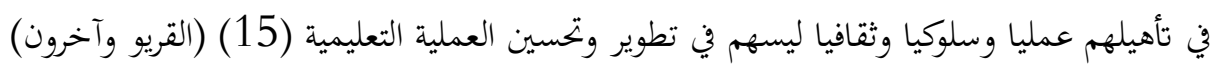
وتُعد الجودة معيار لاستمرار الجامعات وبقاؤها في أداء وظائفها وتحقيق أهدافها، وينبغي على الجامعات مواكبة التطورات

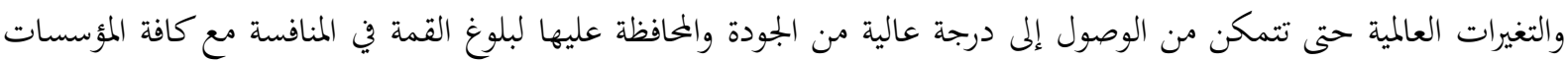

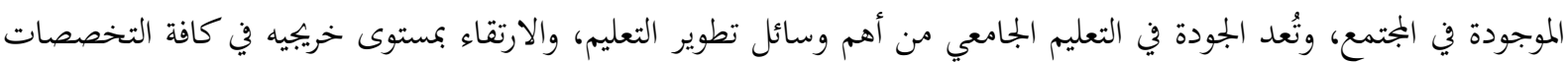
العلمية، حيث اصبحت الجامعة ملزمة باتباع معايير الجودة لضرورةا الملحة التي تمليها التغيرات، والتطورات العلمية المتسارعة التي

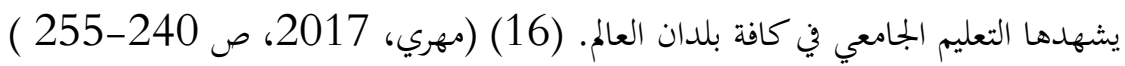

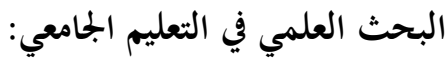

من مهام الجامعة الاهتمام بالبحث العلمي والعناية به باعتباره جزء لا يتجزأ من أنشطتها العلمية لذلك يجب أن تسعى

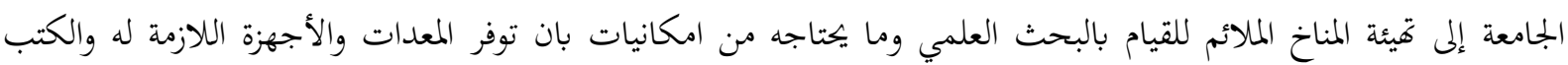
والمراجع بحيث تتيح الفرصة للأساتذة والطلاب استخدامها وبذلك يكون للجامعة دور كبير في عملية التنمية الذاتية لأعضاء هيئة التدريس والطلاب. (17) الخضير ص330

كما أن تطوير العملية التدريسية بالجامعة تعتمد بدرجة كبيرة على عمليات البحث العلمي لذلك فإن الأستاذ الذي يسهم في البحث العلمي بشكل مستمر يمتلك قدرات ومعارف تمكنه من أداء وظيفته التدريسية على أكمل وجه مما ينعكس إيجابيا على لى 
الطلاب وتحصيلهم العلمي إضافة إلى ذلك فإن البحث العلمي يكون له دور فعال في متابعة كل المستجدات العلمية مما يحقق له تطورا علميا في مجال تخصصه والأستاذ الجامعي لا يتوقف إعداده عند تخرجه من الجامعة وحصوله على الدكتوراه بل هو عملية

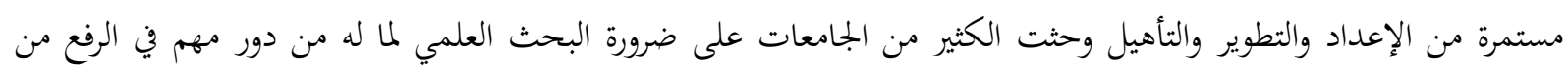

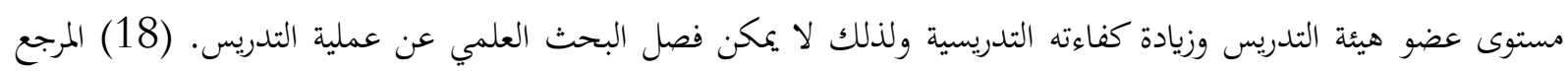
السابق ص330

ولم يعد دور عضو هيئه التدريس يقتصر على العملية التعليمية فقط بل تعدى الأمر إلى البحث والقيام بالدور التربوي

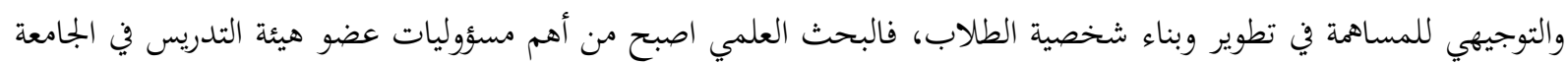
وذلك لما يقوم به من جهد علمي يؤدي إلى تنمية المعرفة وتطويرها في ججال اختصاصه. (19) (الحويطي)

\section{دور البحث العلمي في العملية التعليمية:}

لكي تتمكن الجامعات من تنويع التعليم وربطه بالخطط التنموية لابد من دعمها ماديا ومعنويا لتستطيع القيام بمهامها وتنفيذ أدوارها وتحقيق أهدافها وأداء وظائفها المتنوعة بشكل فاعل، وحتى تسهم في تحسين مهارات أعضاء هيئة التدريس بها

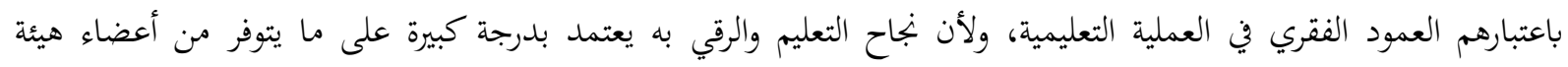

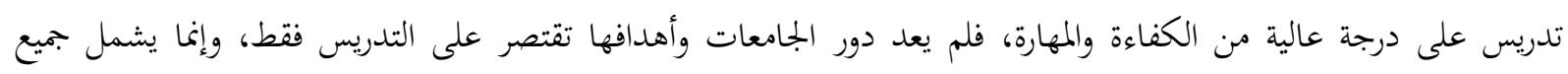
الجوانب الأكاديمية وفي مقدمتها البحث العلمي. (20) (العمايرة )

وتعتمد عملية انتاج المعرفة على البحث العلمي باعتباره عاملا أساسيا في توليد المعارف الجلديدة التي تُسهم في مواجهة

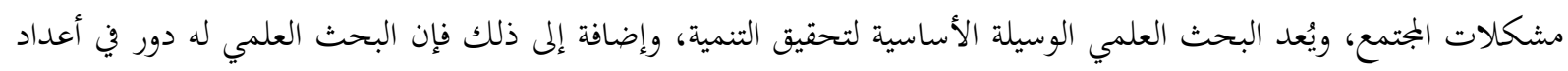

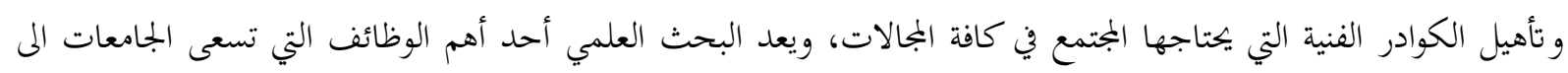
تحقيقها (21) (الحويطي)

ولكي تتمكن الجامعات من تنويع التعليم وربطه بالخطط التنموية لابد من دعمها ماديا ومعنويا من أجل أداء مهامها وتنفيذ أدوارها وتحقيق أهدافها والقيام بوظائفها المتنوعة بشكل فاعل، وحتى تُسهم في تحسين مهارات أعضاء هيئة التدريس بها

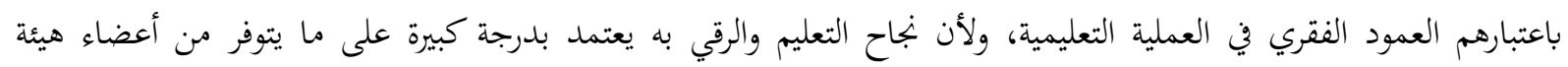

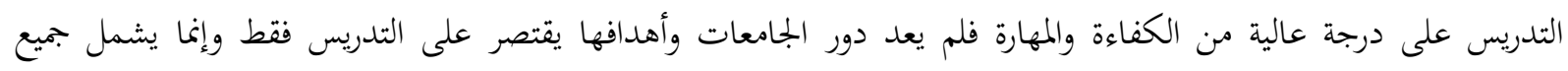

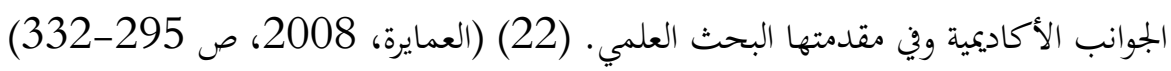

الإطار الميداين للدراسة: يتناول الباحث هنا أهم الخطوات التي تم اتباعها في إعداد الدراسة الميدانية، وذلك على النحو التالي:

لقد تم تطبيق أداة البحث على مختلف كليات جامعة طرابلس، ولاختيار هذه العينة تم تحديد المجتمع الأصلي وهو عبارة

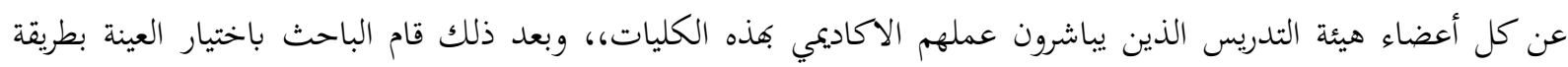
عشوائية بسيطة حيث بلغ حجمها (250) عضوا، وتم جمع (150) استبانة من مجموع الاستبانات الموزعة. 


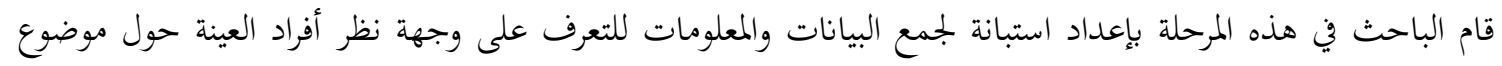
الدراسة، وقد مرت الاستبانة بالعديد من المراحل من أجل تصميمها وظهورها بشكلها النهائي وذلك على النه النحو التالي:

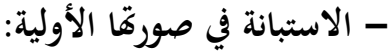

اعتمد الباحث في بناء محاور الاستبانة وإعدادها على الإطار النظري للبحث وبعض البحوث السابقة ذات الصلة المباشرة

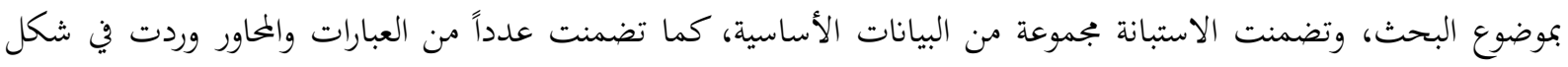
أسئلة مغلقة.

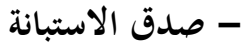

ويقصد به مدى قدرة الاستبانة على قياس الموضوع وصلاحيته لقياس الفرض الذي وضعت من أجله، لذلك قام الباحث بعرض الاستبانة على بجموعة من أعضاء هيئة التدريس المتخصصين في البحث العلمي والعلوم التربوية والنفسية لإبداء آرائهم

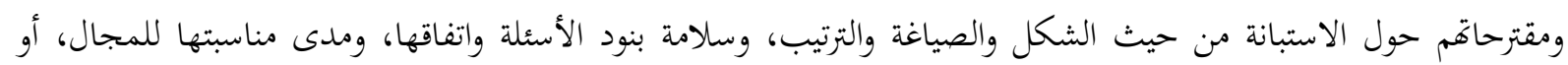

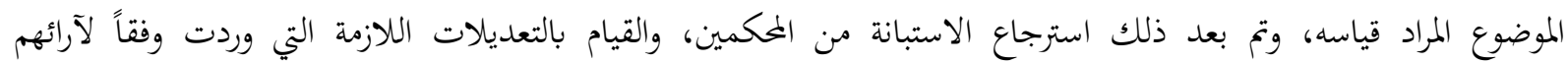
ومقترحاقم.

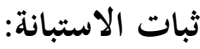

ويقصد به مدى الدقة والاتساق، أي أنه عند استخدام الاستبانة وإعادمّا مرة ثانية في نفس الظروف أو ظروف شبيهة

$$
\text { فإننا نخصل على نفس النتائج. }
$$

استخدم الباحث معادلة (ألفا كرونباخ)، وطريقة التجزئة النصفية على محاور الدراسة، وظهرت النتائج في الجدول التالي. جدول (1) نتائج اختبار ألفاكرونباخ والتجزئة النصفية لمحاور الدراسة

\begin{tabular}{|c|c|c|c|c|}
\hline \multicolumn{4}{|c|}{ المجموع } & \multirow[b]{2}{*}{ المحاور } \\
\hline معامل الثبات سبيرمان & معامل الإرتباط & ألفا كرونباخ & العبار ات & \\
\hline 0.818 & 0.692 & 0.884 & 20 & أهم الصعوبات التي تواجهاك في القيام \\
\hline 0.921 & 0.853 & 0.930 & 10 & اهم مهار ات عضو هيئة التنريس في العملية \\
\hline
\end{tabular}

يتضح من الجدول السابق رقم (1) أن معامل ثبات محاور الدراسة (معامل ألفاكرونباخ) قد تراوح بين (0.884، 0.930)

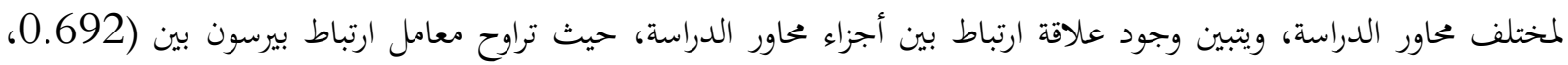

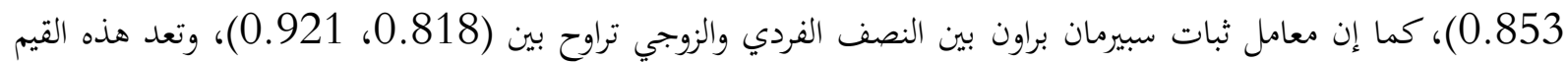
عالية ومناسبة للتحقق من ثبات المقياس.

- الاستبانة في صورتما النهائية استنادا إلى وجهة نظر المحكمين ووفقاً لآرائهم ومقترحاقم قام الباحث بعمل التعديلات اللازمة، ووضع الاستبانة في 


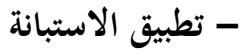

بعد الانتهاء من كل مراحل بناء الاستبانة قام الباحث بعملية التطبيق، وذلك من خلال توزيع الاستمارات على عينة

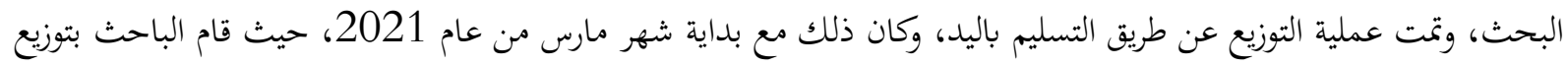

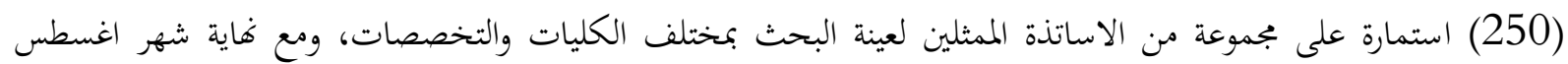

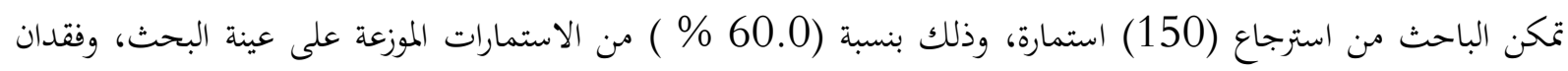
(100) استمارة بسبب إهمال بعض أفراد عينة البحث، وبذلك بلغ عدد الاستمارات الصالحة للتحليل الإحصائي (150) استمارة من أصل (250) استمارة.

\section{الأساليب الإحصائية المستخدمة في الدراسة}

لتحقيق أهداف الدراسة وتحليل البيانات التي تم جمعها من مفردات العينة التي تم اختيارها من مجتمع الدراسة، فقد تم

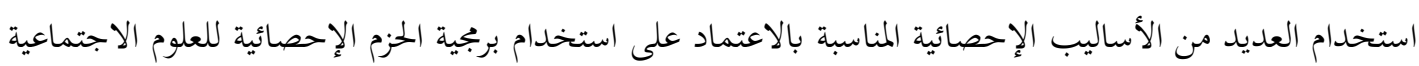
Social Sciences forStatistical Package" "والتي يرمز لها اختصارا بالرمز (SPSS) الإصدار 26، وفي ما يلي بجموعة الأساليب الإحصائية التي قام الباحث باستخدامها: - التوزيع النسبي، والوسط الحسابي، والانحراف المعياري. - اختبار t لعينة واحدة كأحد أساليب الإحصاء الاستدلالي، لإمكانية تعميم النتائج من العينة إلى المجتمع.

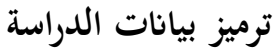

بعد بتميع استمارات الاستبيان استخدم الباحث الطريقة الرقمية في ترميز البيانات حيث تم ترميز الإجابات كما يلي: - المقياس الثلاثي: - n - ne

حيث أنه يقابل كل عبارة من عبارات محاور المتغيرات الأساسية للاستبانة قائمة تحمل الاختيارات التالية وفقاً لمقياس ليكارث الثلاثي: (متوفرة بشدة - متوفرة - غير متوفرة) وقد تم إعطاء كل من الاختيارات السابقة درجات لتتم معالجتها إحصائياً

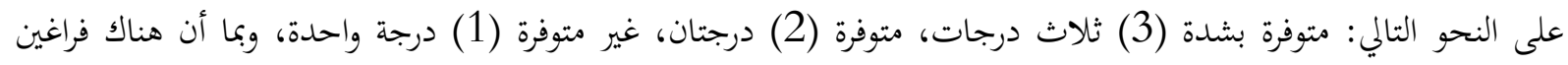
وثلاث اختيارات لذلك تم تحديد المدى لكل اختيار حيث أن المدى = يساوي 0.666، ومن ذلك فإن مدى كل اختيار يتم حسابه كما مبين بالجدول رقم (2) . جدول (2) يوضح مدى الاختيارات المستخدمة بالدراسة

\begin{tabular}{|c|c|}
\hline مدى الاختيار & الاختيار ات \\
\hline من 1 إلى أقل من 1.666 & غير متوفرة \\
\hline من 1.666 إلى أقل من 2.333 & 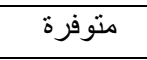 \\
\hline من 2.333 إلى 3 & متوفرة بشدة \\
\hline
\end{tabular}

- المقياس الثنائي: -

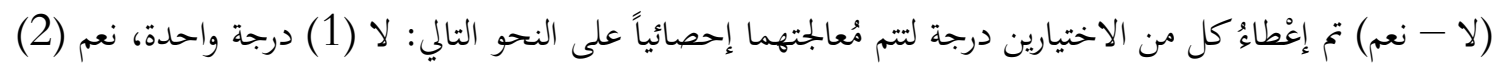

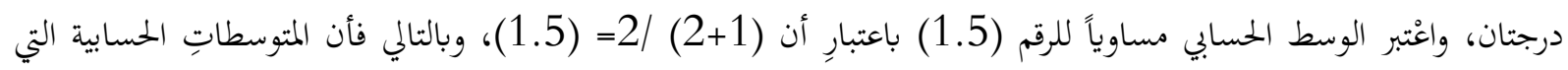


قيمتها أقلُ من (1.5) تُعبر عن درجة موافقة متدنية، والمتوسطاتِ الحسابية التي قيمثُها (1.5) تعبر عن درجة موافقة متوسطة،

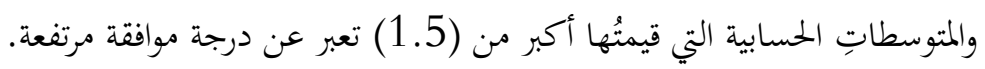

\section{خصائص عينة الدراسة}

جدول (3) خصائص عينة الدراسة

\begin{tabular}{|c|c|c|c|}
\hline النسبة المئوية & التكر ار & الفئة & الخصائص \\
\hline $65.3 \%$ & 98 & ذكور & \multirow{3}{*}{ الجنس } \\
\hline $34.7 \%$ & 52 & إناث & \\
\hline $100.0 \%$ & 150 & المجموع & \\
\hline $30.7 \%$ & 46 & الآداب & \multirow{12}{*}{ الكلية } \\
\hline $10.0 \%$ & 15 & الاقتصاد & \\
\hline $15.3 \%$ & 23 & تربية طر ابلس & \\
\hline $3.3 \%$ & 5 & حاسوب & \\
\hline $12.7 \%$ & 19 & طب & \\
\hline $5.3 \%$ & 8 & الزراعة & \\
\hline $3.3 \%$ & 5 & العلوم & \\
\hline $3.3 \%$ & 5 & القانون & \\
\hline $8.0 \%$ & 12 & صيدلة & \\
\hline $2.7 \%$ & 4 & هندسة & \\
\hline $5.3 \%$ & 8 & تقنية طبية & \\
\hline $100.0 \%$ & 150 & المجموع & \\
\hline $70.0 \%$ & 105 & دكتور اه & \multirow{3}{*}{ المؤهل العلمي } \\
\hline $30.0 \%$ & 45 & ماجستير & \\
\hline $100.0 \%$ & 150 & المجموع & \\
\hline
\end{tabular}

يتضح من الجدول رقم (3) الذي يوضح خصائص عينة الدراسة أها تتميز بالآتي:

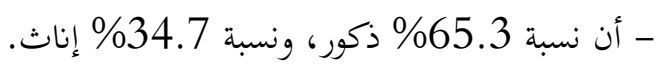

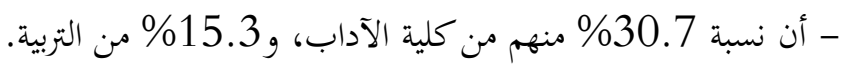

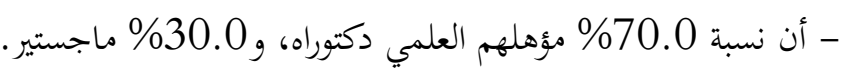

\section{نتائج الدراسة الميدانية وتفسيرها}

تم رصد نتائج الدراسة الميدانية وتفسيرها بحساب التكرارات والنسب المئوية لإجابات افراد العينة على فقرات اداة البحث، وذلك على النحو التالي: 
أولا: الصعوبات التي تواجه أعضاء هيئة التدريس في القيام بالبحث العلمي:

جدول (4) نتائج تحليل أهم الصعوبات التي تواجه عضو هيئة التدريس في القيام بالبحث العلمي

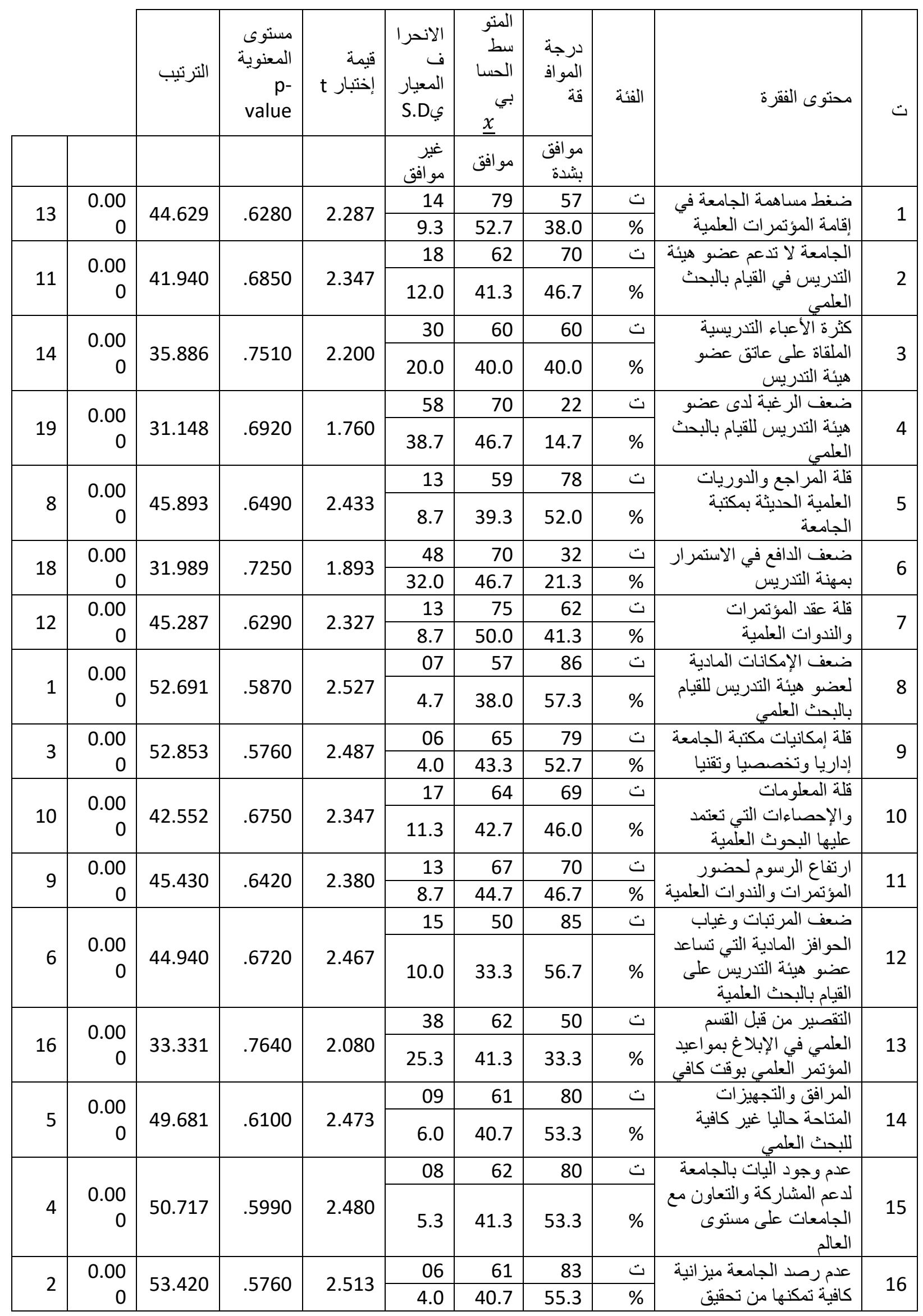




\begin{tabular}{|c|c|c|c|c|c|c|c|c|c|c|c|}
\hline \multirow{10}{*}{ 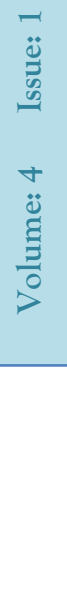 } & & & & & & & & & & خطتها البحتية & \\
\hline & \multirow[b]{2}{*}{7} & \multirow{2}{*}{$\begin{array}{r}0.00 \\
0\end{array}$} & \multirow[b]{2}{*}{49.473} & \multirow[b]{2}{*}{.6090 } & \multirow[b]{2}{*}{2.460} & 09 & 63 & 78 & ت & \multirow{2}{*}{ تسويق البحوثة لالى الجهات } & \multirow[b]{2}{*}{17} \\
\hline & & & & & & 6.0 & 42.0 & 52.0 & $\%$ & & \\
\hline & \multirow[b]{2}{*}{20} & \multirow{2}{*}{$\begin{array}{r}0.00 \\
0\end{array}$} & \multirow[b]{2}{*}{31.128} & \multirow[b]{2}{*}{6870} & \multirow[b]{2}{*}{1.747} & 59 & 70 & 21 & ت & \multirow{2}{*}{ التعمي لدى مهارات البحثي } & \multirow[b]{2}{*}{18} \\
\hline & & & & & & 39.3 & 46.7 & 14.0 & $\%$ & & \\
\hline & \multirow{2}{*}{17} & \multirow{2}{*}{$\begin{array}{r}0.00 \\
0\end{array}$} & \multirow{2}{*}{36.887} & \multirow{2}{*}{.6490} & \multirow{2}{*}{1.953} & 35 & 87 & 28 & $ت$ & \multirow{2}{*}{ تأخر المحكمين في تقييم } & \multirow{2}{*}{19} \\
\hline & & & & & & 23.3 & 58.0 & 18.7 & $\%$ & & \\
\hline & \multirow{2}{*}{15} & 0.00 & \multirow{2}{*}{36.385} & \multirow{2}{*}{.7000} & \multirow{2}{*}{2.080} & 31 & 76 & 43 & $ت$ & \multirow{2}{*}{ في القيام بالبحوث بين الأساتذة } & \multirow{2}{*}{20} \\
\hline & & 0 & & & & 20.7 & 50.7 & 28.7 & $\%$ & & \\
\hline & & $\begin{array}{r}0.00 \\
0\end{array}$ & 75.478 & $\begin{array}{r}.36704 \\
0\end{array}$ & $\begin{array}{r}2.2620 \\
0\end{array}$ & & & & & & الد - الد \\
\hline
\end{tabular}

من الجدول رقم (4) يتضح أن المتوسطات الحسابية حول (أهم الصعوبات التي تواجه أعضاء هيئة التدريس في القيام

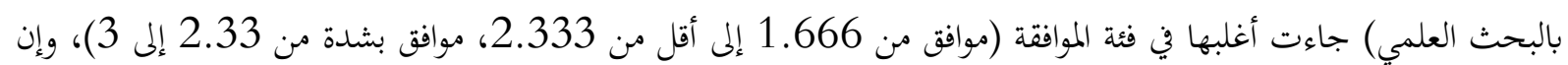

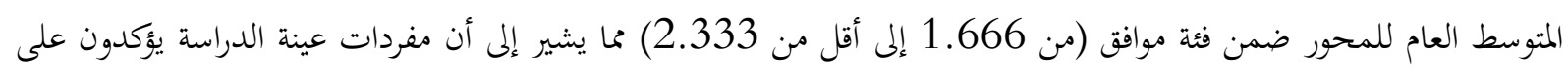

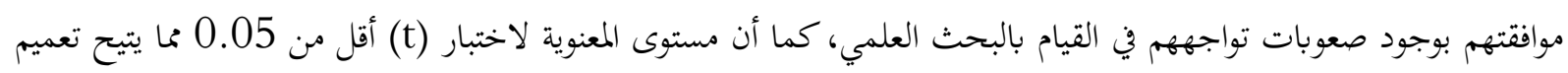
النتائج المتحصل عليها من العينة على مجتمع الدراسة.

ويتضح من خلال الجدول (4) إن من أهم الصعوبات التي تواجه أعضاء هيئة التدريس في قيامهم بالبحث العلمي هي

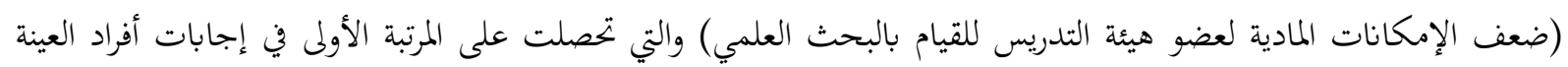

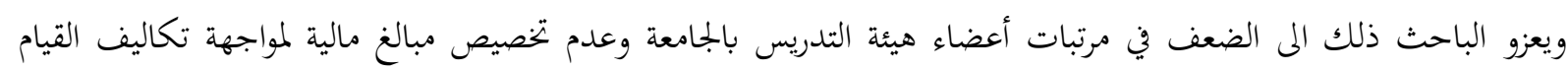

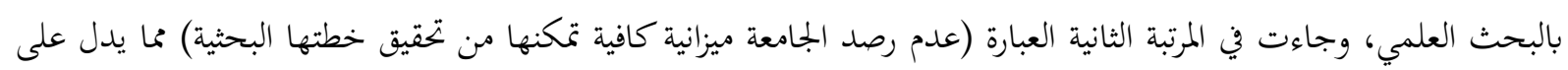

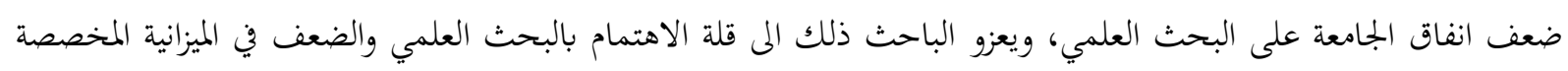

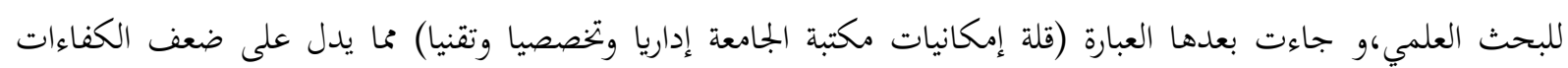

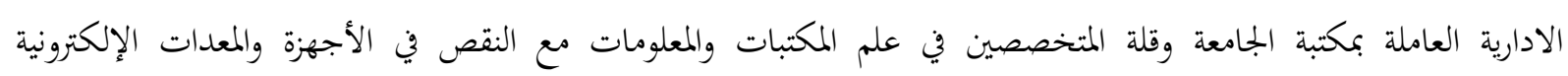

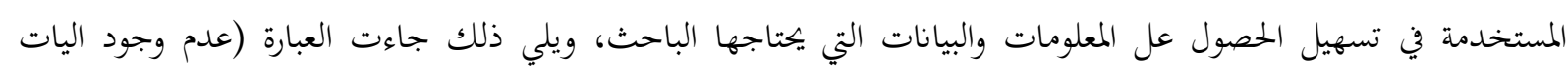

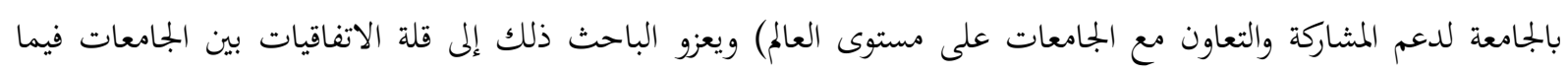

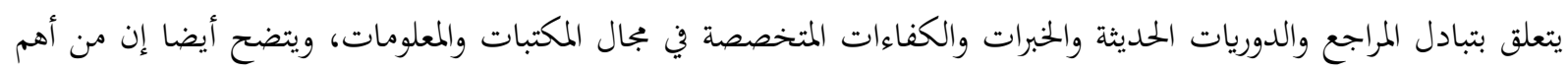

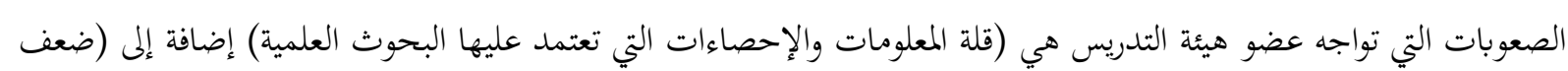
المرتبات وغياب الحوافز المادية التي تساعد عضو هيئة التدريس على القيام بالبحث العلمي.

ثانيا: المهارات التي لا يجيدها عضو هيئة التدريس في العملية التعليمية جدول (5) نتائج تحليل أهم المهارات التي لا يجيدها عضو هيئة التدريس في العملية التعليمية

\begin{tabular}{|c|c|c|c|c|c|c|c|c|c|}
\hline \multirow[b]{2}{*}{ الترتيب } & \multirow{2}{*}{$\begin{array}{c}\text { المعنوية } \\
\text { p- } \\
\text { value } \\
\text { value }\end{array}$} & \multirow[b]{2}{*}{$\begin{array}{c}\text { إختبار } \\
\text { قيمة }\end{array}$} & \multirow{2}{*}{$\begin{array}{c}\text { الانحرياري } \\
\text { S.D }\end{array}$} & \multirow{2}{*}{ 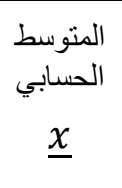 } & \multicolumn{2}{|c|}{ درجة الاستخدام } & \multirow[b]{2}{*}{ فئة } & \multirow[b]{2}{*}{ محتوى الفقرة } & \multirow[b]{2}{*}{ ت } \\
\hline & & & & & لا يستخذم & يستخدم & & & \\
\hline \multirow{2}{*}{2} & \multirow{2}{*}{0.000} & \multirow{2}{*}{$\begin{array}{c}34.54 \\
1\end{array}$} & \multirow{2}{*}{.4780} & \multirow{2}{*}{1.347} & 98 & 52 & $ت$ & \multirow{2}{*}{ مهار ات التعامل مع تكنولوجيا } & \multirow{2}{*}{1} \\
\hline & & & & & 65.3 & 34.7 & $\%$ & & \\
\hline 1 & 0.000 & 35.03 & .4940 & 1.413 & 88 & 62 & $ت$ & مهارات اللغة الإنجليزية & 2 \\
\hline
\end{tabular}




\begin{tabular}{|c|c|c|c|c|c|c|c|c|c|}
\hline & & 4 & & & 58.7 & 41.3 & $\%$ & & \\
\hline \multirow{2}{*}{4} & \multirow{2}{*}{0.000} & \multirow{2}{*}{$\begin{array}{c}34.67 \\
5\end{array}$} & \multirow{2}{*}{.4570} & \multirow{2}{*}{1.293} & 106 & 44 & $ت$ & \multirow{2}{*}{ مهار ات الاتصال الفعال } & \multirow{2}{*}{3} \\
\hline & & & & & 70.7 & 29.3 & $\%$ & & \\
\hline \multirow{2}{*}{7} & \multirow{2}{*}{0.000} & \multirow{2}{*}{$\begin{array}{c}35.17 \\
6\end{array}$} & \multirow{2}{*}{.4360} & \multirow{2}{*}{1.253} & 112 & 38 & ت & \multirow{2}{*}{ مهار ات العرض والتقييم } & \multirow{2}{*}{4} \\
\hline & & & & & 74.7 & 25.3 & $\%$ & & \\
\hline \multirow{2}{*}{8} & \multirow{2}{*}{0.000} & \multirow{2}{*}{$\begin{array}{c}36.15 \\
3\end{array}$} & \multirow{2}{*}{.4110} & \multirow{2}{*}{1.213} & 118 & 32 & $ت$ & \multirow{2}{*}{ مهارة تصميم المقرر الدراسي } & \multirow{2}{*}{5} \\
\hline & & & & & 78.7 & 21.3 & $\%$ & & \\
\hline \multirow{2}{*}{5} & \multirow{2}{*}{0.000} & \multirow{2}{*}{$\begin{array}{c}34.73 \\
2\end{array}$} & \multirow{2}{*}{.4540} & \multirow{2}{*}{1.287} & 107 & 43 & $ت$ & \multirow{2}{*}{ مهار ات استخدام الانترنيت } & \multirow{2}{*}{6} \\
\hline & & & & & 71.3 & 28.7 & $\%$ & & \\
\hline \multirow{2}{*}{3} & \multirow{2}{*}{0.000} & \multirow{2}{*}{$\begin{array}{c}34.62 \\
8\end{array}$} & \multirow{2}{*}{.4600} & \multirow{2}{*}{1.300} & 105 & 45 & ت & \multirow{2}{*}{ المهار ات الإدارية } & \multirow{2}{*}{7} \\
\hline & & & & & 70.0 & 30.0 & $\%$ & & \\
\hline & & 35.06 & 4400 & 1260 & 111 & 39 & $ت$ & الميار ات القبادية & 8 \\
\hline 6 & 0.000 & 4 & .4400 & 1.260 & 74.0 & 26.0 & $\%$ & المهارات الهيادية & 8 \\
\hline 6 & 0000 & 35.06 & 4400 & 1260 & 111 & 39 & $ت$ & معار ات البحث العلى & 9 \\
\hline 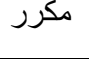 & 0.000 & 4 & 年 & 1.200 & 74.0 & 26.0 & $\%$ & . & \\
\hline 5 & $\cap \cap \cap \cap$ & 34.73 & 4540 & 1287 & 107 & 43 & $ت$ & مهار ات اتخاذ القرارات وحل & 1 \\
\hline مكرر & 0.000 & 2 & .4540 & 1.281 & 71.3 & 28.7 & $\%$ & & 0 \\
\hline & 0.000 & $\begin{array}{c}44.64 \\
5\end{array}$ & $\begin{array}{c}.35425 \\
0\end{array}$ & $\begin{array}{c}1.2913 \\
3\end{array}$ & بمية & & & هم مهار & \\
\hline
\end{tabular}

من الجدول رقم (5) يتضح أن المتوسطات الحسابية حول (اهم مهارات عضو هيئة التدريس في العملية التعليمية) جاءت كلها أقل من 1.5 (لا يستخدم)، وإن المتوسط العام للمحور كذلك أقل من 1.5 (لا يستخدم) منما يشير إلى أن مفردات عينة الدراسة يؤكدون على وجود ضعف في مهارات عضو هيئة التدريس في العملية التعليمية، وان منهم لا يجيد استخدام البعض من

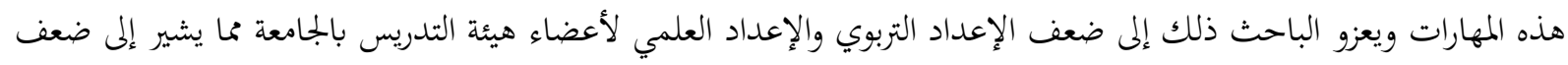
الاهتمام من قبل الدولة بأعضاء هيئة التدريس الذين يشكلون العمود الفقري للعملية التعليمية بالجامعة، كما أن مستوى المعنوية لاختبار (t) أقل من 0.05 مما يتيح تعميم النتائج المتحصل عليها من العينة على مجتمع الدراسة.

النتائج والتوصيات: أولاً النتائج:

حيث خلص البحث إلى بعض النتائج تمثلت في وجود العديد من الصعوبات التي تعيق أعضاء هيئة التدريس في القيام بالبحث العلمي ولعل من أهمها ما يلي: - ضعف الدعم المادي للبحوث العلمية وقلة الاهتمام بها - قصور الجامعة عن تقديم برامج كافية تساعد على القيام بالبحث العلمي - ضعف قدرات بعض أعضاء هيئة التدريس لاستعمالات الحاسب الآلي والانترنت باعتبارها وسائل ضرورية تساعد على القيام بالبحث العلمي. - ضعف قدرات بعض أعضاء هيئة التدريس في استخدام مهارات تصميم المقرر الدراسي ومهارات الاتصال الفعال ومهارات القيام بالبحث العلمي. 


$$
\text { - عدم اسهام الدولة في تشجيع الجامعة على النشر دوليا }
$$$$
\text { - عدم وجود تعاون مع الجامعات الدولية في بجال النشر والبحث العلمي }
$$

- الضعف في الإمكانات المادية لأعضاء هيئة التدريس للقيام بالبحث العلمي، وعدم رصد الجامعة ميزانية كافية تمكنها من تحقيق

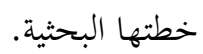

- ضعف الكفاءات الادارية العاملة بمكتبة الجامعة، ونقص المتخصصين في علم المكتبات والمعلومات مع النقص الشديد في الأجهزة والمعدات التقنية المستخدمة في الحصول على المعلومات والبيانات التي يحتاجها أعضاء هيئة التدريس.

- قلة الاتفاقيات بين الجامعات فيما يتعلق بتبادل المراجع، والدوريات الحديثة، والخبرات، والكفاءات المتخصصة في مجال المكتبات، والمعلومات.

- ضعف المرتبات وغياب الحوافز المادية التي تساعد عضو هيئة التدريس على القيام بالبحث العلمي. - قلة المعلومات والاحصائيات التي يعتمد عليها عضو هيئة التدريس في القيام بالبحث العلمي.

التوصيات:

- دعم مشاركات أعضاء هيئة التدريس العلمية إعلاميا، ومنح مكافآت تشجيعية للمتميزين. - اعتبار المشاركات البحثية عاملا أساسيا في تقييم عضو هيئة التدريس، وتحديد آثار قانونية تترتب على غيابها.

$$
\text { - دعم الجامعات في المجالات التي تخدم البحث العلمي. }
$$

- الاتحاه نخو تطوير قدرات أعضاء هيئة التدريس وتنمية مهارات البحث العلمي لديهم بما يتناسب مع المستجدات والتغيرات

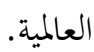

- البحث عن الحلول المناسبة لمواجهة المشكلات التي تعترض عملية القيام بالبحث العلمي. - نشر ثقافة التطوير والتعلم الذاتي مدى الحياة بما يسهم في اكتساب مهارات القيام بالبحث العلمي. - تطوير مهارات التفكير العلمي والإبداعي والابتكاري لدى الاستاذ الجامعي، واكسابه مزيدا من القدرات، والمهارات، والمعارف العلمية، والأكاديمية، والتدريسية، والبحثية.

- الرفع من مرتبات أعضاء هيئة التدريس بالجامعة وتخصيص مبالغ مالية لمواجهة تكاليف القيام بالبحث العلمي. - الرفع من القدرات والمهارات الإدارية والتقنية للعاملين بمكتبة الجامعة. - توفير الأجهزة والمعدات التقنية المستخدمة في الحصول على المعلومات والبيانات التي يحتاجها عضو هيئة التدريس للقيام بالبحث العلمي. - التعاون بين الجامعات فيما يتعلق بتبادل المراجع والدوريات الحديثة والخبرات والكفاءات المتخصصة في مجال المكتبات والمعلومات. 
آية عبدالله احمد النويهي، دور الجامعات في تقدم البحث العلمي وأثره على المجتمع، المركز الديمقراطي العربي، 2014.

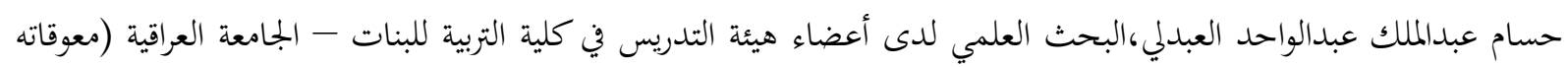

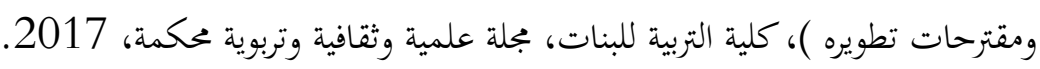

خضير بن مسعود الخضير،التعليم العالي في المملكة العربية السعودية بين الطموح والإنجاز،جامعة الملك فهد للبترول والمعادن، مكتبة العبيكان، 1419 هـ

شريفة كلاع، الجامعات العربية والبحث العلمي قراءة في واقع البحث العلمي ومعيقاته،المؤتمر الدولي التاسع - الجزائر 18-19 أغسطس 2015.

شناف خديجة عبدالحميد مهري، معايير ضمان جودة التعليم العالي - عرض لبعض النماذج العالمية، مجلة الدراسات والبحوث

$$
\text { الاجتماعية،العدد (24) ديسمبر } 2017 .
$$

عبدالقادر الحمد صالح، التنمية المهنية لأعضاء هيئة التدريس بالجامعات الليبية في ضوء الأدوار المتغيرة للجامعة، رسالة دكتوراه غير منشورة، كلية الدراسات العليا، جامعة القاهرة، 2011.

عماد ولد علي، العلاقة بين عوامل نجاح البحث العلمي وانتاجية البحث العلمي في الجامعات الفلسطينية، مجلة الجامعة العربية

$$
\text { الامريكية للبحوث، بجلد (5)، العدد، (1)، } 2019 .
$$

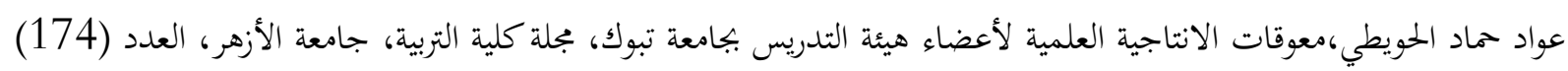

$$
\text { الجزء الثاني، يوليو، } 2017 .
$$

عيسى قدادة،و آخر، تقويم جودة أعضاء هيئة التدريس في مؤسسات التعليم العالي،المجلة العربية لضمان جودة التعليم العالي،

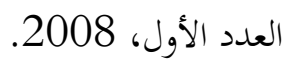

اللجنة الشعبية العامة سابقا، قرار رقم (285) لسنة 2006 بشأن لائحة أعضاء هيئة التدريس الوطنيين بالجامعات ومؤسسات

$$
\text { التعليم العالي }
$$

مجدي عبدالكريم حبيب،رؤية مستقبلية للتعليم الجامعي العربي (المتطلبات - الأدوار - التحديات - المعايير)، استراتيجيات التعليم

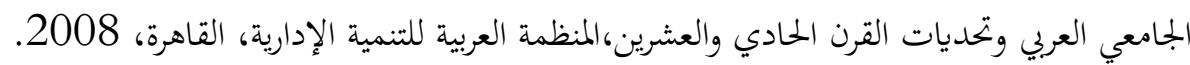

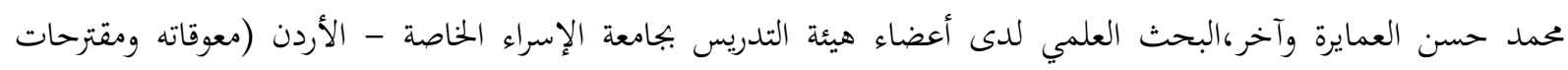

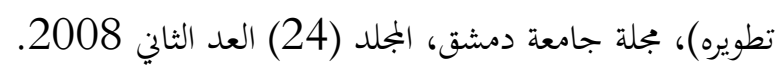

محمد عبدالسلام القريو وآخرون، دور إدارة الجودة الشاملة في تحسين أداء مؤسسات التعليم العالي اللبيي، المؤتمر العلمي الرابع

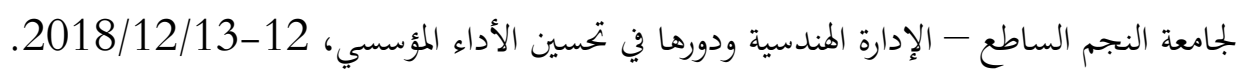

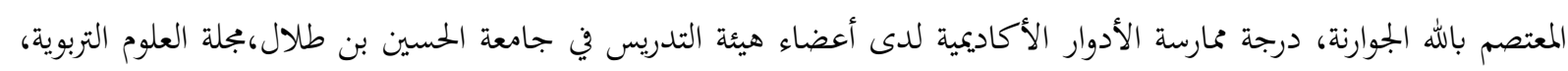

$$
\text { المجلد (42)، العدد (3)، } 2015 .
$$

منتهى عبد الزهرة محسن، الصعوبات التي تواجه البحث العلمي في جامعة بغداد من وجهة نظر التدريسيين، مجلة البحوث التربوية والنفسية، العدد الثاني والثلاثون، 2011.

هشام يعقوب مريزيق، وآخر، قضايا معاصرة في التعليم العالي، الطبعة الأولى، 2008. 